\title{
Partial germline reversions can increase VRC07 potency and breadth
}

\author{
RS Rudicell", I Georgiev, Z Yang, S O'Dell, Y Kwon, J Zhu, X Wu, PD Kwong, JR Mascola, GJ Nabel \\ From AIDS Vaccine 2012 \\ Boston, MA, USA. 9-12 September 2012
}

\section{Background}

VRC01 and related antibodies target the CD4 binding site (CD4bs), are broadly neutralizing and highly potent, and have undergone high levels of somatic hypermutation. To optimize such antibodies for passive immunization and to further understand antibody development, we reverted three CD4bs antibodies towards their putative germlines and analyzed the effects on breadth and potency. Interestingly, we also identified key germline reversion mutations that increased neutralization potential.

\section{Methods}

Structure/function-based analyses were used to design partially reverted heavy and light chains based on the clonally-related antibodies VRC01, NIH45-46, and VRC07. Mature CDRs were maintained and framework regions were back-mutated. The antibodies were expressed, purified, and tested for binding to gp120 by ELISA. Neutralization against a panel of tier 2 HIV-1 pseudotyped viruses was determined for select antibodies.

\section{Results}

The heavy chains of VRC01, NIH45-46, and VRC07 are $42 \%, 41 \%$, and $44 \%$ somatically mutated from their germline precursor, while the light chains are 29\% (VRC01/07) and $27 \%$ (NIH45-46) somatically mutated. We began by reverting over half of the heavy chain somatic mutations and over one-third of the light chain somatic mutations to their germline residue identities. An iterative design approach was used, and we systematically re-introduced mature residues to the partial germline reversions. Most mutants retained the ability to bind gp 120 and neutralize diverse HIV-1 pseudoviruses, albeit with lower breadth and/or potency than their mature counterparts.

Vaccine Research Center, NIAID, NIH, Bethesda, MD, MD, USA
Additionally, we found 3 partial-germline reversion mutations that increased VRC07 potency.

\section{Conclusion}

Here, we showed that in most cases mature framework regions in addition to mature CDRs were required for highest neutralization potency and breadth. However, three framework germline reversion mutations increased potency 2-3 fold. These partial reversions are being combined with other mutations, including those that modulate Fc effector function, to optimize the antibody function for passive transfer in NHPs and humans.

Published: 13 September 2012

doi:10.1186/1742-4690-9-S2-P101

Cite this article as: Rudicell et al:. Partial germline reversions can

increase VRC07 potency and breadth. Retrovirology 2012 9(Suppl 2):P101.
Submit your next manuscript to BioMed Central and take full advantage of:

- Convenient online submission

- Thorough peer review

- No space constraints or color figure charges

- Immediate publication on acceptance

- Inclusion in PubMed, CAS, Scopus and Google Scholar

- Research which is freely available for redistribution
() Bïomed Central 